\title{
Cross-Culture Influences on Interpersonal Relationship in Communication Management A Case Study: Foreign Supervisors PK Chinese Employees in Foreign-Invested Enterprises
}

\author{
Xiaoyan Zhang $^{1}$ \& Lan Huang ${ }^{2}$ \\ ${ }^{1}$ The Foreign Language Department, Beijing Institute of Petrochemical Technology, Beijing, China \\ ${ }^{2}$ School of Economics \& Management, Beijing Institute of Petrochemical Technology, Beijing, China \\ Correspondence: Xiaoyan Zhang, The Foreign Language Department, Beijing Institute of Petrochemical \\ Technology, Beijing, China. E-mail: zxy@bipt.edu.cn
}

Received: March 6, 2013 Accepted: April 15, 2013 Online Published: May 24, 2013

doi:10.5539/ijbm.v8n12p117 URL: http://dx.doi.org/10.5539/ijbm.v8n12p117

\begin{abstract}
China has taken a gradual reform in the enterprise system and human resources management has been changed day by day in foreign-invested enterprises. A subsequent challenge of this globalization is the managerial influences of multicultural management. This paper is to clarify and analyze the problems which stem from cultural conflicts between foreign supervisors and Chinese subordinators in Chinese foreign-invested enterprises. Other than that, this paper also tries to find some feasible ways to improve the current situation. A qualitative approach with a single case study of "Email Gate" in China is employed in the study.
\end{abstract}

Keywords: foreign-invested enterprises, email gate, multicultural communication management, cultural conflicts, cross-culture interpersonal communication strategies

\section{Introduction}

\subsection{Foreign-Invested Enterprises in China}

Foreign-invested enterprises have already become the engine of China economic development. There are about 450 in the world-top 500 enterprises which have founded their factories in China (Hu jingyan, 2005). Moreover, some enterprises have still increased their investments. By China's 27 years' reform and openness, foreign-invested enterprises in China have integrated with Chinese economic system and generated approximately one-third industrial production value of China and hired more than 22 million Chinese employees (Hu jingyan, 2005). Most of the Chinese employees make great contribution in the process of the market deploitation in China for foreign-invested enterprises.

\subsection{Issues on Interpersonal Communication in Foreign-Invested Enterprises of China}

Seeking a job in a foreign-invested enterprise is the ambition for thousands upon thousands new graduates in China. But actually, not all such "marriages" produce success stories. Working in foreign-invested enterprises is not easy for majority Chinese and many of them feel that cultural differences create prodigious obstacles, especially in dealing with interpersonal communication with their foreign supervisors. In the same way, the fact which can not be ignored is that many foreign supervisors in foreign-invested enterprises experience difficulties and dilemmas in handling the interpersonal relationship with their Chinese subordinates. Statistic shows that due to culture gaps, $15 \%$ of those joint venture or pure foreign venture companies in China terminated their business earlier than expectation with an important reason of instability ("Foreign investment in China", 2004). According to a study on "Cultural Conflicts in Foreign-invested Enterprises", the most significant factor among the reasons for high turnover rate seems to be the awful interpersonal relationship stemmed from cultural conflicts within the multi-culture workplaces. Many Chinese employees interviewed in above study complained that they were not completely accepted by their foreign senior colleagues. Some complained that their foreign supervisors knew little about Chinese culture and had "stereotyping" about China, yet refused to learn even a bit more (Han, 2005). 


\subsection{The Importance of Interpersonal Relationship in Cross-Culture Communication Management}

Culture molds the relational schemas that personnel use to coordinate, make decision, negotiate motivate, and communicate in organizations. With regard to foreign-invested enterprises in China, the management of organizations is especially complex owing to culture differences. Handling interpersonal relations must be careful for both foreign supervisors and local subordinates. Knowing culture differences on both sides will foster better understanding and ensure the stability of human resource of foreign-invested enterprises. On one hand, positive interpersonal relations can facilitate foreign supervisors to convey his objectives, assign jobs or tasks and motivate Chinese employees smoothly. On the other hand, close interpersonal relations with managers also make subordinates productive and be willing to give feedbacks.

\subsection{Theoretical Basis}

\subsubsection{Cross-Culture Management}

Cultural traditions and values have been identified as key factors that shape and determine the way the interpersonal relationship. According to a survey conducted by an international magazine "Electronic World" in the global scale, cultural difference is ranked on the top of the factors that hinder the development of multinational business and create particular challenges for intercultural business (Zhuang Enping \& Luo Hao, 2005). Yu Lei (2006) in his popular work "Leave the MNEs" also indicates the culture conflict is one of the important reasons for many local employees who leave foreign-invested enterprises in recent years in China. So cross-culture management research in multinational organizations is urgent and necessary, especially in China, a country that attaches much importance to traditional culture and cultural values.

\subsubsection{Individualism vs. Collectivism}

According to Hofstede (2005), individualism and collectivism is identified as one of the cultural dimensions. Westerns from America, Canada, Great Britain, and Australia are less interdependent and focus on individual. Chinese culture, by contrast, is usually conceived as a society with more collective orientation. Chinese people's identity is in a large extent defined according to their relationship to a group such as family, school or employer (Shirley Chan \& Bonnie Nq, 2003). Successful business in China is based on relationship building, 'guanxi' and harmony (Ying Lin \& Natalie Stoianoff, 2004). Chinese prefer team work or business to be conducted on a personal and warm level. The group harmony is primary. Interpersonal relationships serve as the main basis for developing and maintaining smooth group work or business operations. Foreign investors in China need to understand and adapt to this cultural factor.

\subsubsection{High and Low Context}

High and low context is also generally used to describe cultural difference between societies. The terms 'high context' and 'low context' are popularized by Edward Hall (Jennifer E. Beer, 1997-2003). High context refers to societies or groups like China where people have close connections over a long period of time. Many aspects of cultural behavior are not made explicit because most members know what to do and what to think from years of interaction with each other. In contrast, low context refers to societies like America where people tend to have many connections but of shorter duration or for some specific reasons. In these societies, cultural behavior and beliefs may need to be spelled out explicitly so that those coming into the cultural environment know how to behave (Jennifer E. Beer, 1997-2003).

\section{Method}

\subsection{Research Design}

In this study, we would like to have an in-depth firm level view to answer the research question: "What are the barriers on firm level in interpersonal relationship in foreign-invested enterprises of China?"

Qualitative research offers in-depth responses to questions or discussions, allows for a richer study of the subject, and allows for information to be gathered and analyzed in a subjective way that would otherwise be entirely missed by a quantitative approach (Ronald L. Jackson II, Darlene K. Drummond, \& Sakile Camara, 2007). So the qualitative approach with a single case study, which can provide more details and depth, is preferred in our study.

\subsection{Case Selection: Chinese Secretary P.K. Foreign Boss}

"Email Gate" happened in EMC on April 2006. It may be the most influential and typical affair that shows the friction between foreign supervisors and Chinese employees due to cultural difference in Chinese foreign-invested enterprises. Hu Rui, a senior secretary in EMC, drafted an E-mail to fight against her boss. The email was later spread out widely on Internet and well-known in Chinese foreign-invested enterprises. 
This case can be employed to exemplify the present situation of the interpersonal communication between foreign supervisors and Chinese subordinates in foreign-invested enterprises.

\subsubsection{The Profiles of Two Characters in "Email Gate"}

EMC: "the world leader in products, services, and solutions for information management and storage". Its headquarter lies in US (EMC website). Loke, Soon Choo: EMC-China president administers the Chinese business of EMC as a whole. He has more than 20 years high-level management experience in IT domain, including IBM, Simons, and Oracle.

HURUI, EMC senior secretary, used to work for several CEOs (TOM.news, 2006).

\subsubsection{The Correspondences between Loke Soon Choo and His Secretary Hu Rui}

From: Loke, Soon Choo

Sent: Saturday, April 08, 2006 1:13 AM

To: Hu, Rui

Cc: Ng, Padel; Ma, Stanley; Zhou, Simon; Lai, Sharon Subject: Do not assume or take things for granted

Rebecca, I just told you not to assume or take things for granted on Tuesday and you locked me out of my office this evening when all my things are all still in the office because you assume I have my office key on my person.

With immediate effect, you do not leave the office until you have checked with all the managers you support this is for the lunch hour as well as at end of day, OK?

Hu rui replied in Chinese. The following is the translation of Hu rui's reply.

Sent: 2006 年 4 月 10 日 13:48

To: Loke, Soon Choo

Cc: China All (Beijing); China All (Chengdu); China All (Guangzhou); China All (Shanghai); Lai, Sharon

Subject: FW: Do not assume or take things for granted

Soon Choo,

First of all, what I did was absolutely correct. I locked the door based on security consideration. As you know, thieves do exist in Beijing; I could not take the responsibility of losing anything.

Secondly, you had your own keys, but you forgot to bring them, it's your own fault, not mine. The main responsibility of this accident was at your side; please don't throw your own mistake to somebody else.

Thirdly, you do not have the right to interrupt or control my private time. I work eight hours per day here. Lunch time and time after work belong to me, not you. Please remember it!

Fourthly, since I joined EMC, I do my duty with honors and responsibilities. I work overtime frequently, and I don't complain anything about it. But if you request me to work overtime for the matter that is totally not related to my work itself, I can't accept it!

Fifthly, although you are my boss, you still need to mind your tone of voice, because it is the basic politeness.

Finally, I want to highlight I didn't assume anything because I didn't have time to do it, and it was not necessary at all.

\subsubsection{Sequence of the Matter}

8 Apr. 1:13am, Loke forwarded an e-mail to HURUI and send it to other high-level managers;

10 Apr. 1:48pm, HURUI wrote back to Loke and send it to all of Manger level of EMC in China;

11 Apr. This e-mail was spread out widely and aroused fervent arguments on Internet ("The rational analysis about EMC "e-mail affair", 2006).

\subsubsection{The Consequence of the Matter}

This email soon became the hottest topic in Chinese foreign-invested enterprises. Many people made comments on the affair on Internet. Hu rui was betitled the most "arrogant" secretary in history. More than 10 pages of comments and 1000 signatures of the supporters were added to the original e-mail, with almost all supporting opinions. However, the secretary was fired finally. Later, Loke resigned. "Email Gate" results in a lose-lose situation. 


\section{Results}

\subsection{Issue Analysis}

In order to answer the research question, the analysis is set to be based on some documents, previous studies and theories from the Internet and libraries.

\subsubsection{The Cultural Background of Loke and $\mathrm{Hu}$}

The two characters in "Email Gate" come from different countries with different social context though both cultures are within Asia. Singapore is a society which is gradually "making a transition from a largely British-colonial-style culture to a sophisticated mix of Asian and Western cultures" (David Lammers, 2005). A lot of people are brought up with western philosophy and influenced by western culture and customs more or less (Aitchison, Jim, 2005). Culture diversity is embodied in language, religion, moral value and organization management. As a Singaporean, Loke majors in business administration in Singapore and has more than 20 years high-level managerial experience in many multinational Corporations, including IBM (US), Simons (Germany), and Oracle (US) (Tom.news).

When talking about the complex Chinese culture, some people conceive that cultural differences more possibly exist between East and West rather than Singapore and China. But some findings in a survey uncover the fact that Singaporean feel more unacquainted with Chinese culture even than some Japanese, American and European (International education, 2006). And business failures of some Singaporean in China exemplified that cultural differences exist between these two countries with cultural affinity (Zheng, 2003). Taking the western culture as the native cultural complementarities, Singapore represents some kinds of hybrid culture. Similarly, the corporation culture and management in Singapore adopt the administrating system based on western philosophy (CMIW, 2006).

Loke and Hu Rui are representatives from different cultural background. Therefore, "Email Gate" can be seen as a cross-cultural friction on interpersonal relationship in the multicultural organization. The great stir and much resonance to "Email Gate" show that the conflicts of interpersonal communication between foreign supervisors and the Chinese subordinates are universal phenomena. These are the most common friction existing in Chinese foreign-invested enterprises. The remarkable influence of the "Email Gate" may exemplify for the long-term accumulation of contradictions between foreign supervisors and Chinese employees and even for a concentrated eruption in Chinese foreign-invested enterprises.

\subsubsection{Dimensions of National Culture}

In the case of "Email Gate", the differences of four dimensions of national culture may lead to the conflict of interpersonal relationship between Loke Soon Choo and Hu Rui.

\section{1) "Guanxi" in China}

Chinese have some particular concepts on interpersonal relationships. "Guanxi" is defined as relationships or social connections based on mutual interests and benefits (Yang, 1994). In Chinese business world, "Guanxi" is also understood as the network of relationships among various parties that cooperate together and support one another. The Chinese businessmen mentality is very much one of "You scratch my back, I'll scratch yours." Regardless of business experiences in ones home country, effective and long -term business operation relies heavily on the right "Guanxi" in China. By getting the right "Guanxi" network, the inevitable risks and barriers you'll encounter in running business will be minimized. Therefore, "Guanxi" plays an important role in Chinese business world and is so essential to successful management strategy in China (Business Chinese, 2009). This cultural characteristic is unwonted in western culture and is toughly to be comprehended by those foreign supervisors. So the lack of understanding it will hinder the effective supervisor-subordinate communication in cross-culture management.

\section{2) Task-focused Orientation vs. Social-emotional Orientation}

Most supervisors in Chinese foreign-invested enterprises are foreigners. Most of them are used to handling personal relationships in the way of western management. Mor Barak (2005) states that in western societies personnel in organizations focus much on elements which is directly relevant to task and goals rather than members involved. In contrast, in Asian societies social-emotional ties are tight based on the interdependent culture. Emotional concerns and interpersonal harmony are regarded as essential to task success. The lack of interpersonal harmony will interrupt the teamwork that needs much cooperation to fulfill objectives. For example, it's very common for a manager to pursue activities with their workgroups out of work hours for relationship building or motivating their subordinates in Chinese organizations. Michael Miles (2000) in his 
research on the difference leadership practice between western countries and China also reveals that western managers are inclined to a more rational approach. Salary and benefit differentials are usually employed to encourage productivity. In contrast, it's hard for Chinese managers to inspire subordinates without high quality of the relationship with employees.

In Michael's survey, a respondent from Shanxi province in China claimed that he would not quit the current job though he disliked it because he liked the manager whom he worked with. A high quality relation with managers and peers is the most essential factor for him to make the choice. Therefore, Chinese employees have higher level of loyalties to their managers than to their companies to some extent. Negative personal relations will hinder foreign supervisors to assign tasks and motivate employees.

The conflict caused by the two different orientations is embodied in the "Email Gate". As a CEO, Loke Soon Choo is in charge of the EMC's business in China. However, he has very strong personal character and is not good at cultivating relationships with subordinates, customers and partners during the business operation. As a result, the majority of the personnel have negative impression on him. Loke Soon Choo's failure lies in his low EQ. (China Business Post, 2006). The way he handles interpersonal relationships is unacceptable under China's culture context. Chinese employees prefer to be regarded as close team players or supportive partners while not just a tool to finish tasks (Yu Huajun, 2006).

\section{3) Direct Communication vs. Indirect Communication}

Mor Barak (2005) in his international management studies defines direct communication as explicit and straightforward words when exchanging information. In contrast, indirect communication primarily bases on fuzzy type and the abstract language foundation. Samovar, Larry A. (2004) in his research about cultures' impact on communication points out that Westerners are free to communicate and easy to overlook the identity and status of communication interpersonal relationship, but Chinese believe that friendly and interpersonal harmony is the maintenance of equal relations as a link. Samovar attributes the aggressive behavior of Westerns to the culture "valuing individualism, competition, and freedom of expression". In such a culture, people are encouraged to display the inner feelings directly in interacting with others. Direct and assertive communication will not be considered as offending others. On the contrary, Chinese culture favors indirect hinting for preserving "face" and harmony. People tend to employ face-saving communication strategies such as indirectness to avoid conflict and maintain interpersonal harmony with others, particularly when putting forward advice, criticizing others or conveying bad news. For instance, people seldom say "No" so as not to make the other person lose face or embarrassed. The following two pictures vividly show the difference between indirect communication and direct communication.
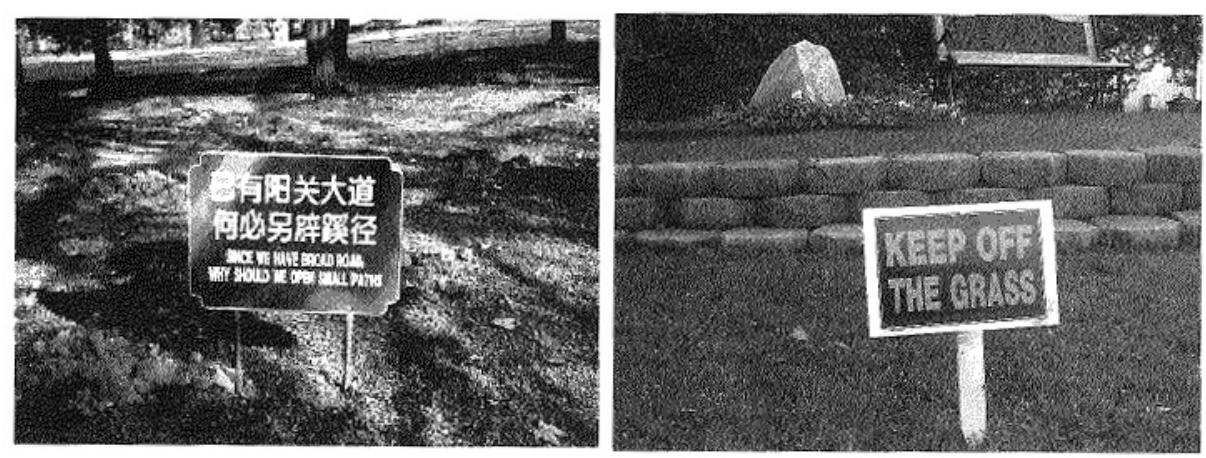

Figure 1. "Since we have broad road, why should we open small paths" (China, indirect communication) \& "Keep off grass" (U.S., direct communication)

Source: Managing Diversity toward a Globally Inclusive Workplace, 2005

In the original text of the email presented in the introductory part, every sentence is expressed by Loke Soon Choo in a very direct and sharp way with strong inclination of blame and order in a Chinese employee's view. Forwarding the email to other supervisors by Loke Soon Choo is the last straw which irritated Hu. The excessive direct communication way is beyond the extent of tolerance and hurts Hu's feelings deeply. As a senior secretary, Hu certainly feels humiliated in EMC and considers her leader's demand is out of reason. Hu's response shows how serious the consequence is if direct communication can not be employed delicately 
in foreign-invested enterprises.

Another case also can demonstrate the different way of communication may lead to misunderstanding between foreign supervisors and local employees. Ye Sheng (2004), a general manager in ECOPRITY Consulting (CHINA) Co., Ltd., in his article mentions a true story happened in Philips Electronic Co., Ltd in China. A vice manager of the Human Resource Department was an American. He once talked to an excellent Chinese subordinate and expected to know his personal development plan in five years. To his puzzled, the employee did not give the feedback directly all the time. What he said was all concerned about the development and promotion system of the whole company. After the talk they all complained to the general manager of the Human Resource Department. The American manager thought the subordinate could not give the implicit response while the Chinese employee felt the supervisor was impatient and rude during the communication. Actually Chinese employees usually show their modesty firstly when facing promotion opportunities. They display their expectation to the high position or high salary in indirect way with fear of being mocked for having audacious ambition or being envied by colleagues.

Generally speaking, being aggressive and straightforward are not highly valued in Chinese culture. Direct communication undoubtedly can facilitate the flow or exchange of information and ideas. However, a friendly atmosphere will make the team productive and successful. With regard to the impersonal relations in foreign-invested enterprises, indirectness as an important communication strategy for foreign supervisors may motivate teamwork, preserve the harmony and stability and avoid further misunderstanding, contradiction and conflicts.

4) Face

Face is called mien-tzu (mian zi) in Chinese. It refers to an individual sense of positive image in the context of social interaction (John G. Oetzel \& Stella Ting-Toomey, 2003). As an old saying goes, "people live for face as trees grow for bark", most Chinese people value face a lot. According to Echo Shan (2005), in a survey conducted by China Youth Daily, over 93 percent of the 1,150 respondents claim they attach much importance to their mianzi, which concerns people's decency, personality and dignity. 74.9 percent of respondents regard public gaffes as the most humiliating thing and more than a half of the respondents feel ashamed of showing ignorance before others. Mien-tzu plays an important role in explaining Chinese communication styles and establishing interpersonal relationships. Chinese people value mien-tzu no matter how high or low one is in status. Saving mien-tzu is vital not only for satisfying oneself, but also for respecting others' mien-tzu in return.

According to Noel Kreicker (2006), saving face and giving face are intuitive to Chinese and losing face is to be avoided at all costs. Americans prefer "telling it like it is" and are unaccustomed to reading cues from indirect cultures where face and harmony are the first order of business. In workplace Chinese discuss everything in advance and consider meetings as an official "ceremony" where the already commonly agreed decision will be announced. This is important in the way of "giving and keeping face". The Americans and Germans in contrast inform the attendants in a meeting about the hard and necessary facts. The decision-making process takes place within the meeting.

Ignoring cross-cultural differences in interaction may induce non-rational response. In the original text of the email, Loke Soon Choo puts all the blame on the secretary. Furthermore, he forwards the email to other supervisors. Because of losing "mian zi", the resentment to Loke make Hu reply the e-mail in more furious words and sent it to more colleagues. In face of cultural conflicts, if the two sides have no patience to seek the unanimous orientation, but only complain or take out their resentment on one another, the little conflict is to be magnified.

In general, based on the case analysis, some documents and pervious theories, we would like to build a table (Table 2) to clearly illustrate the differences of interpersonal communication between Chinese culture and Western culture. By comparing communication style and staff behavior, with the consideration from a multi-cultural perspective and of the national culture influence, the barriers on firm level in cross-cultural interpersonal communication in foreign-invested enterprises of China will be unveiled. 
Table 2. The influence of different cultures on interpersonal communication between Chinese culture and Western culture

\begin{tabular}{|c|c|c|c|c|}
\hline & $\begin{array}{c}\text { interpersonal } \\
\text { communication \& } \\
\text { social connections }\end{array}$ & $\begin{array}{l}\text { orientation in handling } \\
\text { work and maintaining } \\
\text { interpersonal } \\
\text { relationships }\end{array}$ & $\begin{array}{c}\text { verbal } \\
\text { communication }\end{array}$ & Face (mien-tzu) \\
\hline $\begin{array}{l}\text { Chinese } \\
\text { culture }\end{array}$ & $\begin{array}{l}\text { collective } \\
\text { orientation }\end{array}$ & $\begin{array}{l}\text { social-emotional } \\
\text { orientation }\end{array}$ & $\begin{array}{l}\text { direct and } \\
\text { assertive } \\
\text { communication }\end{array}$ & $\begin{array}{l}\text { value face a lot and focus } \\
\text { on the requirement of } \\
\text { dignity and respect }\end{array}$ \\
\hline $\begin{array}{l}\text { Western } \\
\text { culture }\end{array}$ & $\begin{array}{l}\text { less } \\
\text { interdependent } \\
\text { and focus on } \\
\text { individual }\end{array}$ & $\begin{array}{c}\text { task-focused } \\
\text { Orientation }\end{array}$ & $\begin{array}{l}\text { display the inner } \\
\text { feelings and } \\
\text { thoughts } \\
\text { indirectly }\end{array}$ & $\begin{array}{l}\text { focus on personal } \\
\text { independence }\end{array}$ \\
\hline
\end{tabular}

\subsection{Strategies for Cross-Cultural Management in Foreign-Invested Enterprises of China}

An in-depth study of the topic is presented so as to awake foreign supervisors' awareness of cultural importance in foreign-invested enterprises of China. Through analyzing and discussing the reasons of the conflict deriving from cultural difference, a practical case study is provided to managers to help them have a picture about what barriers culture brings to the cross-cultural management. We find that the key issue faced by foreign supervisors and local employees in foreign-invested enterprises is how to establish and maintain harmonious interpersonal relationship across a clear and undeniable culture barrier. Thus it is inevitable that measures or strategies will be implemented to avoid such economic and human resource losses.

\subsubsection{Recommendations in Terms of the Case}

\section{1) To Loke Soon Choo}

The right communication way is to admit that he forgets to bring the key on that day and gets locked in the office. Then he can consult with the secretary to remind him of locking the office after work. Complaining or blaming her in public is an inappropriate way of communication. He can give advices to his subordinates privately.

\section{2) To Hu Rui}

She should reply the email in English and indicate both sides had duties. She should not forward the email to all supervisors and employees. It's better to ask him for his advices or offer her own suggestions in order to avoid the circumstance.

\subsubsection{General Recommendations}

\section{1) To Foreign Supervisors}

It's useful to set up training sessions for foreign supervisors to learn how to establish and maintain harmonious interpersonal relationships in foreign-invested enterprises of China. Foreign experts or foreign supervisors who have worked in China many years with rich experience can be invited to give the lecture.

Surveillance and command only lead to the distance and alienation between foreign supervisors and Chinese subordinates. As a foreign supervisor, pursuing activities with your workgroups out of work hours can facilitate relationship building and motivating your subordinates.

Using indirect communication strategy also can avoid misunderstanding and maintain interpersonal harmony with your subordinates, particularly when pointing out their faults.

In a business context, mutual creation of value is dependent on mutual learning and mutual adaptation. Language training is not only focus on local employees. Supervisors who can speak local language are more popular and welcomed in Chinese foreign-invested enterprises.

2) To Chinese Subordinates

The related cultural training to local employees in foreign-invested enterprises is necessary. Learning foreign culture, customs and traditions will help Chinese subordinates to understand foreign supervisors' behaviors.

Discuss rather than confront. Resentment and feelings of hostility can not solve problems. Don't overreact to 
criticism of foreign supervisors and confront with them because that just breeds more conflicts. Dissatisfying your work means that they have their own idea on how that work should be done, so ask them for their advice on how your work can be improved.

\section{Discussion}

\subsection{Limitations of Research}

This study has several limitations. One of the limitations is that only one methodology is applied in the study, this would result in not having thoroughly answered research questions. A better project would involve multiple methodologies tools to supplement and complement each other.

Another limitation is the small number of responses received due to limited resources. The problems, which are discussed in this study, may not happen in all of foreign-invested enterprises of China. But these problems typically exist during the cross-cultural management.

\subsection{Conclusion}

After reviewing the previous studies and related theories, we summarize the differences of dimensions of national culture and find the barriers of cross-cultural interpersonal communication in foreign-invested enterprises of China. The findings of this study indicate that the barriers stem from the national culture's influence on different ways of communication and behaviors of people with different identity. Briefly, the barriers of cross-cultural communication in foreign-invested enterprises of China come from the aspects blow:

- Different ways of interpersonal communication and social connections

- Different orientation in handling work and maintaining interpersonal relationships

- Different ways of verbal communication

- Lack of mutual understanding to national culture

Generally speaking, in this paper we discuss and analyze the common issue in foreign-invested enterprises via a typical case study in China. Lacking of cross-cultural understanding makes it hard for cross-cultural management practice. The different growth environment and cultural background may cause misunderstanding and disharmony in multicultural organizations. Serious conflicts on interpersonal communication may cause lose-lose situation and barriers to global success. Smooth downward and upward communication is based on mutual respect, understanding and support. Thus, both sides should be culturally aware and sensitive, trying to adapt to other part's behavioral patterns and lifestyles. The effective cross-culture interpersonal communication strategies are in great need and should be valued highly for reaching the win-win situation between supervisors and subordinates in Chinese foreign-invested enterprises.

\section{References}

Aitchison, J. (2005). Cultrual Minefields: How to /develop a Pan-asian Campaign. In Now my advertising works! An advertiser's guide to what works and what doesn't in Asia. Singapore: Prentice Hall.

Business Chinese. (2009). "Guanxi": An Important Chinese Business Element. Retrieved from http://www.xcnchinese.com/www/Daily_Life/Business/

China-Language, Culture, Customs and Etiquette. Retrieved from http://www.kwintessential.co.uk/resources/global-etiquette/china-country-profile.html

China-Window.com. (2004). Chinese Cultural Values and Their Implications in Business. Retrieved from http://www.china-window.com/china_business/china_business_tips/chinese-cultural-values-a.shtml

CMIW. (2006). The Impact of Asian Development on Chinese organization management. Retrieved from http://www.cmiw.cn/HTML/2006-5-11/15225.html

David Lammers. (2005). Singapore -- Giant shadow looms. Retrieved from http://web.lexis-nexis.com.ezlibproxy1.ntu.edu.sg/universe/document?_m=8894bac6246e9b7620e4cb0c6 fef18e\&_docnum=33\&wchp=dGLbVzW-zSkVb\&_md5=4b32ac8723e5c14837f66adc9a0a03d1

Echo Shan. (2005). 'Mianzi' of Chinese weighs a lot, comes at a price. Retrieved from http://www.chinadaily.com.cn/english/doc/2005-08/08/content_467216.htm

EMC. (2006). Retrieved from http//www.emc.com

Enping, Z., \& Hao, L. (2005). The Different Evaluation Standards to Personnel in Western and Eastern Organizations.

Retrieved

from 
http://www.ciicsh.com/ciicsh/media_insight/media_info_detail.asp?co_id=627

Foreign investment in China. (2004). From friction to syncretism. Retrieve from http://www.ficmagazine.com/article.php?FicID=27\&Colum=\%E5\%B0\%81\%E9\%9D\%A2\%E6\%96\%87\%E $7 \% \mathrm{AB} \% \mathrm{~A} 0$

Geert Hofstede \& Gert Jan Hofstede. (2005). Cultures and Organizations: Software of the Mind. New York: McGraw-Hill.

Han, X. (2005). Cultural Conflicts blocked Chinese employees in FIEs. Retrieved from http://www.dfzb.cn/ReadNews.asp?NewsID=21059

Huajun, Y. (2006). IT organization's Comments on EMC Email Incident. Retrieved from http://it.people.com.cn/GB/42891/42893/4369988.html

International education. (2006). Talk about the cultural difference of China and foreign coutries. Retrieved from $\mathrm{http} / / /$ www.wafjc.com/html/yingyutiandi/zhongwaiwenhua/2006/0807/73.html

Lei, Y. (2006). Leave the MNEs. Ecomomic Management Pulications.

Michalle, E. M. B. (2005). Managing Diversity toward a Globally Inclusive Workplace. Sage Publications, Inc.

$\mathrm{Mu}, \mathrm{M}$. (2004). Difference and Interpretation of Cultures in Foreign Investment and Enterprises. Retrieved from http://house.runsky.com/homepage/rich/hr/node4105/userobject1ai529928.html

Noel, K. (2006). Rising Tigers, Hidden Dangers. Retrieved from http://www.iorworld.com/filebin/pdf/Rising_Tiger_Hidden_Dangers_CC.pdf

Qi, S. (2001). Five initiators of Guangdong Robust abdicated all together. Retrieved from http://finance.sina.com.cn/b/20011217/155544.html

Ronald, L., Jackson, II., Darlene, K. D., \& Sakile, C. (2007). What is qualitative research? Qualitative Research Reports in Communication, 8(1), 21-28. http://dx.doi.org/10.1080/17459430701617879

Samovar, L. A., \& Richard, E. P. (2004). Communication Between Cultures (5th ed.). Belmont, CA: Wadsworth/Thomson Learning.

Shirley, C., \& Bonnie, N. (2003). KM and Asian Cultures: Are there advantages and disadvantages when sharing knowledge in the East? Retrieved from $\mathrm{http}: / / \mathrm{www}$. destinationkm.com/articles/default.asp?ArticleID $=1030$

Sohu News. (2006). The rational analysis about EMC "e-mail" affair. Retrieved from http://club.news.sohu.com/r-minjian-587727-0-1-0.html

TOM news. (2006). Woman secretary PK foreign boss. Retrieve from http://news.tom.com/2006-04-26/000N/13567394.html

Web Forum. (2006). The rational analysis about EMC "e-mail"affair. http://club.news.sohu.com/r-minjian-587727-0-1-0.html

Xinhua.net. (2005). Cross-national enterprises are quickening their paces. Retrieved from http://net.xinhuanet.com/cdz/2005-01/31/content_3659349.htm

Yang, M. M. (1994). Gifts, Favors, Banquets: The Art of Social Relationship in China. Ithaca, NY: Cornell University Press.

Ye, S. (2004). Cross-culture Conflict in Foreign-capital Enterprises. Retrieved from http://info.china.alibaba.com/news/detail/v5000060-d5367884.html

Ying, L., \& Natalie, S. (2004). Foreign Investment in China: The Cross-Cultural Dilemma. Retrieved from http://www.austlii.edu.au/au/journals/MqBLJ/2004/1.html

Zheng, J. (2003). Singaporean should strengthen their trade character. Retrieved from http://eu.ynst.net.cn/portal/read.jsp?infoPickId=186738385818019 